\title{
Parameters Matching and Simulation on a Hybrid Power System for Electric Bulldozer
}

\author{
Hong Wang ${ }^{1}$, Qiang Song ${ }^{2, 凶}$, Feng-Chun SUN ${ }^{3}$ and Pu Zeng ${ }^{4}$ \\ ${ }^{1,2,3,4}$ National Engineering Laboratory for Electric Vehicles, Beijing Institute of Technology, China \\ $\triangle$ Author to whom correspondence should be addressed; E-Mail: songqiang@bit.edu.cn;
}

Tel.: +86-10-6894-9243; Fax: +86-10-6894-9243.

Keywords: duel-motor-driving bulldozer; parameter matching; mathematical model; simulation

\begin{abstract}
Hybrid power systems, formed by two motors and high-energy-density batteries in appropriate ways, provide high-performances and high-efficiency power for electric bulldozer. This paper firstly constructs the mathematical model of driving motors system based on the design of dual-motor-driving propulsion system for bulldozer. The requirements of several main parameters are analyzed. Secondly, by using the setting values from a bulldozer, simulation work is implemented, and parameters of the hybrid power system are matched, and finally, based on MATLAB/Simulink, dynamic models for the dual-motor-driving hybrid power system is established, and the simulation results are discussed.
\end{abstract}

\section{Introduction}

In recent years, the number of construction machinery is increasing significantly with the social development. The negative effects of the ever-increasing number of construction machinery have adversely impacted both energy sustainability and overall air quality. Even worse, the energy generated from oil yields the lowest energy efficiency, with an approximate rate of only $20 \%$. Consequently, many studies have been undertaken to address these energy issues, especially regarding the utilization of electricity as a viable replacement for oil. Caterpillar in the United States produced a revolutionary D7E electric drive track-type bulldozer with electric-drive system in March, 2008. Compared with internal-combustion driving track-type bulldozers, D7E can yield greater fuel efficiency by nearly $10 \%$ to $30 \%$, and at the same time enhance drive train efficiency and take lower life-cycle maintenance costs.

Structure of duel-motor-drive electric bulldozer. As showed in fig.1, many parts of mechanical transmission can be cut down for dual-motor-driving electric bulldozer. The paths of electric power and mechanical power are tandem to each other in the series configurations, respectively.

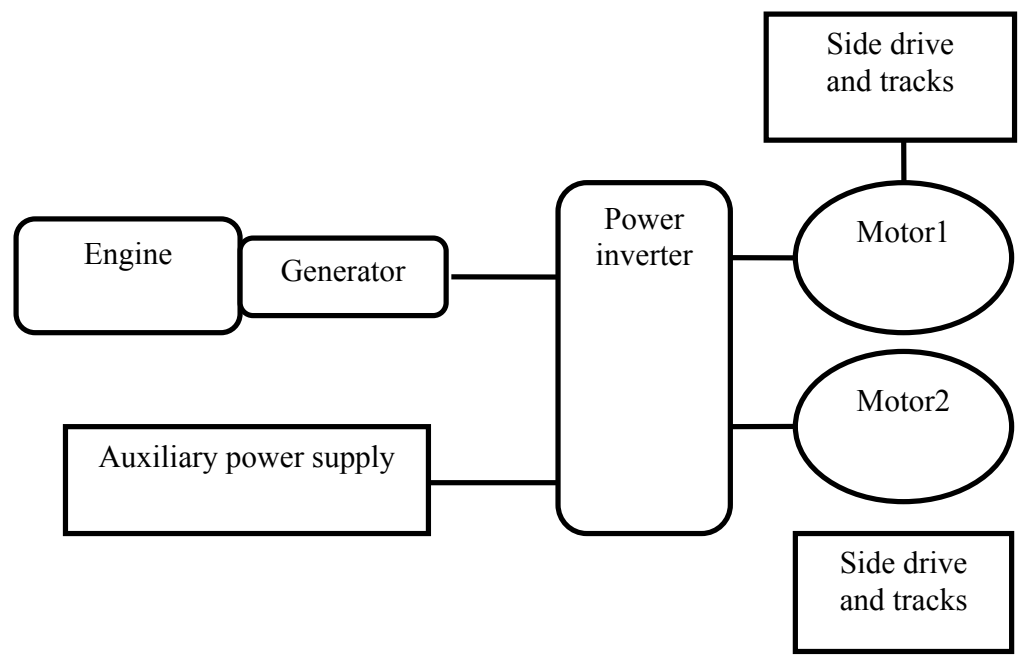

Fig.1 Structure of duel-motor-drive electric bulldozer 
Dual-motor-drive electric bulldozer uses the integrated controller to control the motors on the both sides of the bulldozer independently and transfers electric energy from the generator and auxiliary power supply into mechanical energy in order to drive the bulldozer.

The bulldozer's working states can be divided into following six stages: soil-cutting, soil-transportation, returning, climbing, turning and accelerating. Considering these stages, their driving mathematical models are established in section 2.

Contributions of this research. This research paper details the authors' efforts to construct the mathematical model of driving motors system for the dual-motor-drive bulldozer and match the parameters of the hybrid power system.

The model of this hybrid power system is further studied base on MATLAB/Simulink, and then the simulation was done.

Organization of the paper. This paper is organized as follows: in Section2, the mathematical model and parameters matching of the hybrid power system are presented; in Section 3, the model of the hybrid power system based on MATLAB/Simulink is established. Then, conclusions and possible future research are discussed.

\section{Mathematical models}

Power, Torque, rated and maximum speed are important factors in parameter matching of driving motors system. These parameters are considered specially during driving motors' mathematical modeling progress ${ }^{[1]}$.

Maximum speed $n_{\max }$. The selection of maximum speed mainly based on the highest velocity of the bulldozer, actual motor design capabilities and the size requirements. Maximum speed and side gear ratio should meet the following relationship.

$$
\begin{aligned}
& n_{\max }=\frac{u_{\text {max }} i}{0.377 r} \\
& i=i_{0} * i_{1}
\end{aligned}
$$

where $r$ is radius $(\mathrm{m}) ; i$ is side gear ratio; $u_{\max }$ is maximum velocity of the bulldozer; $i_{0}$ is final drive ratio; $i_{1}$ is reduction gear ratio.

Rated speed $n_{e}$. Rated speed should be the long-term continuous operation speed point. Therefore, the rated speed should be matched according to conventional operation speed of the bulldozer.

$$
n_{e}=\frac{u_{e} i}{0.377 r}
$$

where $u_{e}$ is bulldozer normal operation velocity.

Motor's torque $T$. As the dual-motor-drive power system, $T$ here discussed is single motor's torque. Motor's torque should meet power need during the whole working progress.

During the soil-cutting stage, the bulldozer cuts soil at a constant driving speed (the speed here is selected as $2.5 \mathrm{~km} / \mathrm{h}$ ). At the end of soil-cutting progress (the largest mound is formed before the blade) while the blade is going to lift, cutting soil depth reaches maximum, which is also the maximum moment of power consumption and torque requirement. So the torque needed in this moment is regarded as the motor's torque.

In the whole working process, the bulldozer's speed is less than $6 \mathrm{~km} / \mathrm{h}$ and the acceleration is small, so the air resistance and the inertial resistance are ignored when the mathematical models is established.

The single motor's torque is given according to the follow states and relationships ${ }^{[2]}$. 


$$
T=\frac{\left(f G+F_{T}\right) r}{2 i \eta}
$$

where $f$ is the rolling resistance coefficient; $\eta$ is the efficiency from the traction motor to the track; $F_{\mathrm{T}}$ is the operating resistance $(\mathrm{N})$;

Operating resistance $\left(F_{\mathrm{T}}\right)$ can be given as

$$
\begin{aligned}
& F_{T}=F_{1}+F_{2}+F_{3}+F_{4} \\
& F_{1}=10^{6} B_{1} h_{p} k_{b} \\
& F_{2}=G_{t} \mu_{1} \cos \alpha=\frac{V \mu_{1} \cos \alpha}{k_{s}} \\
& F_{3}=10^{6} B_{1} X \mu_{2} k_{y} \\
& F_{4}=G_{t} \mu_{2} \cos \delta^{2} \cos \alpha \\
& V=\frac{B_{1}\left(H-h_{p}\right)^{2} k_{m}}{2 \tan \alpha_{0}}
\end{aligned}
$$

where $F_{1}$ is soil-cutting resistance $(\mathrm{N}) ; F_{2}$ is pushing resistance of mound before blade $(\mathrm{N}) ; F_{3}$ is frictional resistance between ground and blade $(\mathrm{N}) ; F_{4}$ is horizontal component of frictional resistance while soil rises along blade $(\mathrm{N}) ; k_{\mathrm{b}}$ is cutting resistance per unit area $(\mathrm{Mpa}) ; B_{1}$ is dozer's blade width $(\mathrm{m}) ; h_{\mathrm{p}}$ is average cutting depth $(\mathrm{m}) ; G_{t}$ is the gravity of the mound before bulldozing plate; $\mu_{1}$ is friction coefficient between soil and soil; $\mu_{2}$ is friction coefficient between soil and blade; $\alpha$ is slope $\left({ }^{\circ}\right) ; \gamma$ is gravity per cubic meter $\left(\mathrm{N} / \mathrm{m}^{3}\right) ; V$ is volume of the mound before bulldozing plate; $k_{s}$ is loose degree coefficient of soil; $k_{m}$ is fullness degree coefficient of soil; $H$ is dozer blade height $(\mathrm{m}) ; \alpha_{0}$ is the natural slope angle of the soil $\left(^{\circ}\right)$; $K_{\mathrm{y}}$ is cutting resistance per unit area after blade pressed into the soil (Mpa); $X$ is length of the worn blade contacting with ground $(\mathrm{m})$; and $\delta$ is cutting angle of the dozer blade $\left(^{\circ}\right)$.

Motor's power $P$. Motor's torque, power and motor motor's speed should meet the following relationship.

$$
T=9549 \frac{P}{n}
$$

Simulation. Based on the motor's mathematical model above, the motor's parameters are simulated for a bulldozer. The main simulation parameters of bulldozer and working conditions are set in tab. 1.

Tab.1 Simulation parameters for dual-motor-driving bulldozer

\begin{tabular}{|c|c|c|c|c|c|}
\hline $\mathrm{y}$ & $\mathrm{G}[\mathrm{kg}]$ & $\mathrm{H}[\mathrm{m}]$ & $\mathrm{B}_{1}[\mathrm{~m}]$ & $k_{s}$ & $\mathrm{~L}[\mathrm{~m}]$ \\
\hline 0.86 & 28000 & 1.58 & 3.54 & 1.06 & 3.05 \\
\hline $\mathrm{h}_{\mathrm{p}}[\mathrm{m}]$ & $\mathrm{k}_{\mathrm{b}}[\mathrm{MPa}]$ & $\mu_{1}$ & $\mu_{2}$ & $\mathrm{f}$ & $\mathrm{X}[\mathrm{m}]$ \\
\hline 0.2 & 0.06 & 1.0 & 0.5 & 0.1 & 0.01 \\
\hline
\end{tabular}

In order to change the bulldozer's structure as little as possible, original side gear ratio $i$ is adopted in this mathematical model of the motor.

Based on the above motor's mathematical model, the driving motor's parameters for a dual-motor-drive electric bulldozer are simulated. Simulation result is shown in fig.2. 


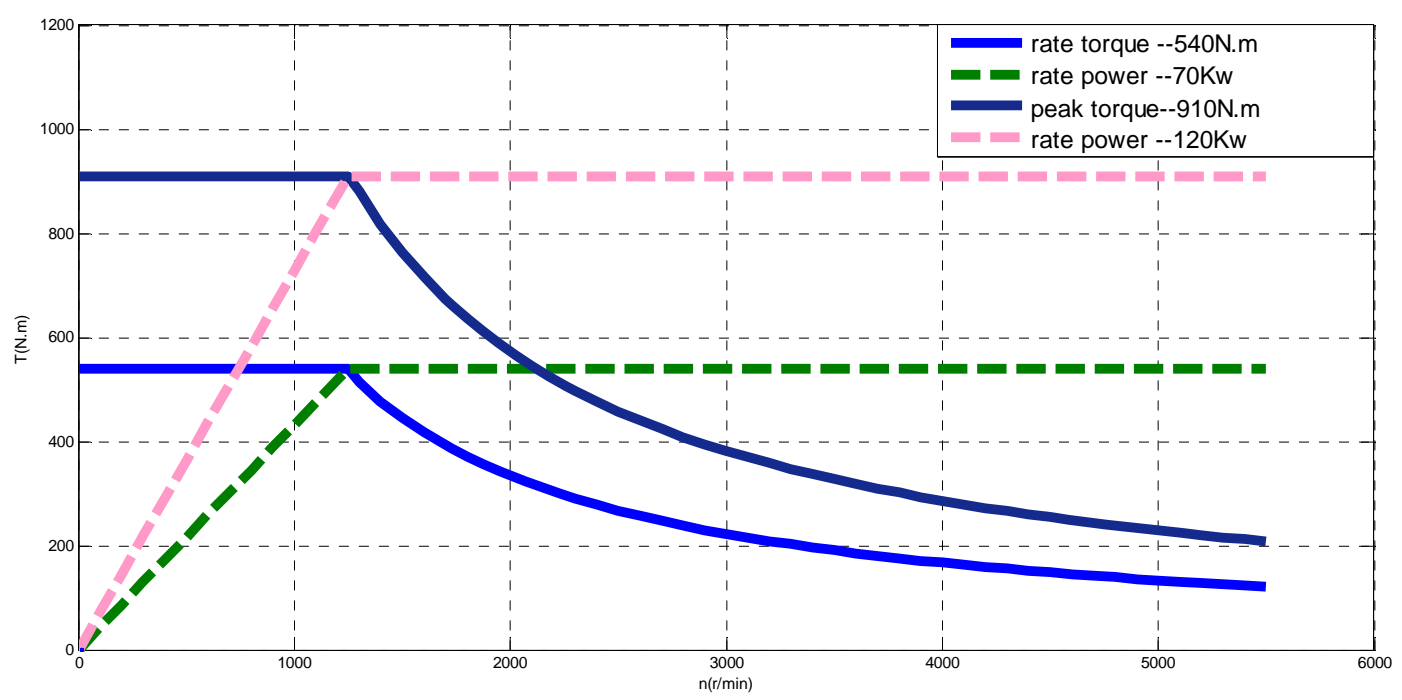

Fig.2 Single motor's characteristic curves

\section{Dynamic Modeling for Hybrid Power System}

Model of the Engine. The engine's fuel injection quantity is adjusted by rack position ${ }^{[3]}$. The torque is obtained by the position of rack position and the speed of the engine. The model of the engine is shown in figure 3 .

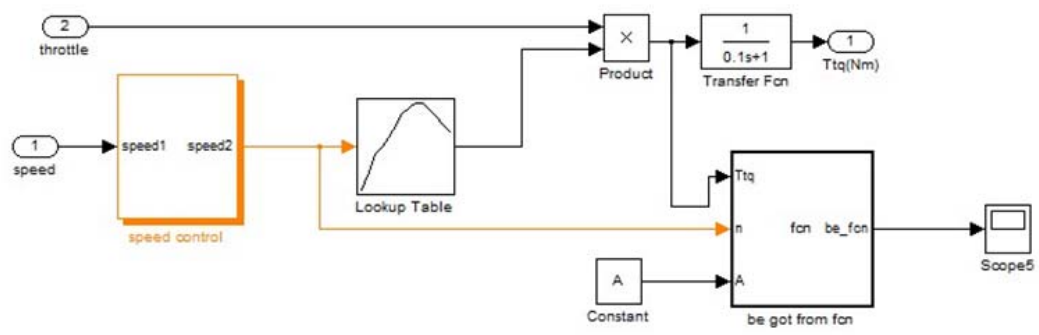

Fig.3 Model of the Engine

Model of the Generator. The model of generator-rectifier is established by equivalent circuit method $^{[4]}$. The generator can be regarded as a controllable voltage source in the electrics. DC bus voltage is related to DC bus current. The model is shown in Figure 4. The inputs are engine torque and DC bus current; the output is the electromotive force.

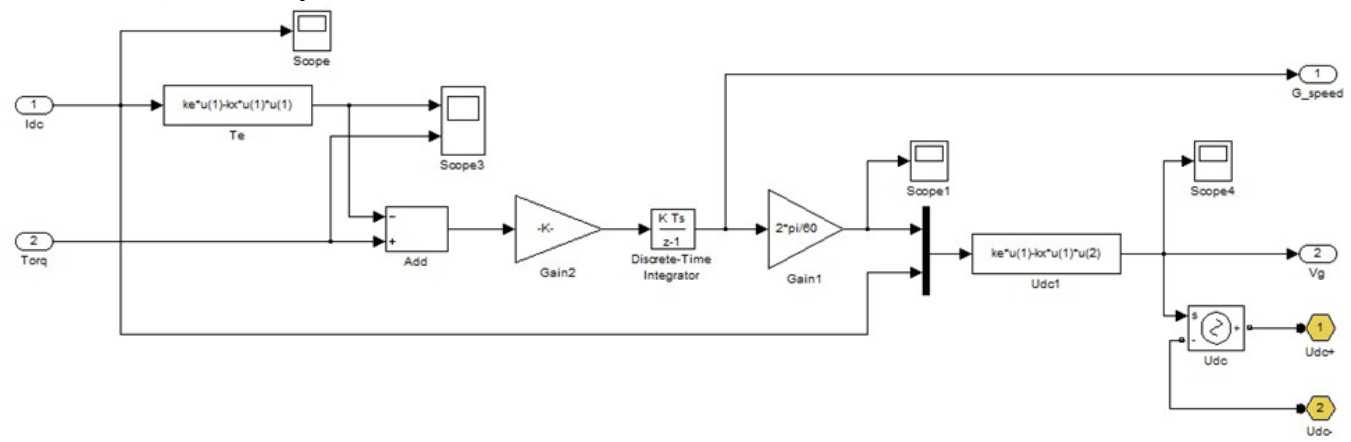

Fig.4 Model of the Generator-rectifier

Dynamic Model of the Motor. The driving motor system is regarded as a controllable current source $^{[5]}$. The model is shown in Figure 5. 


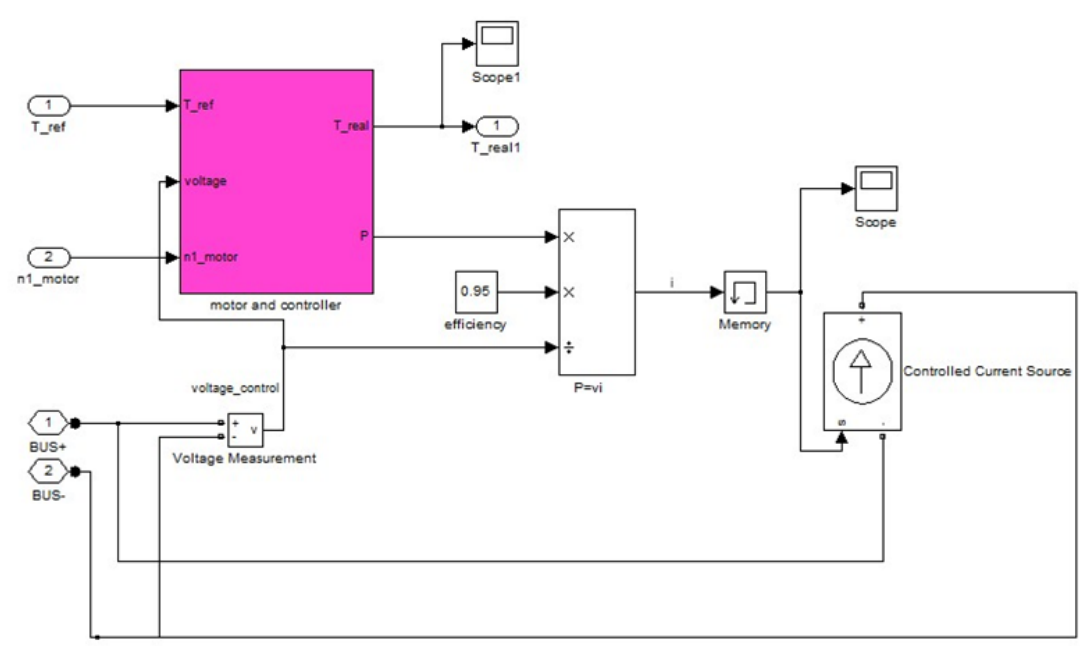

Fig.5 Model of the Motor

\section{Simulation Experiments}

According to the typical working characteristic, the above hybrid power system is simulated. The fuel consumption rate $\left(b_{e}\right)$ comparison between traditional and hybrid power system is shown in fig.6.

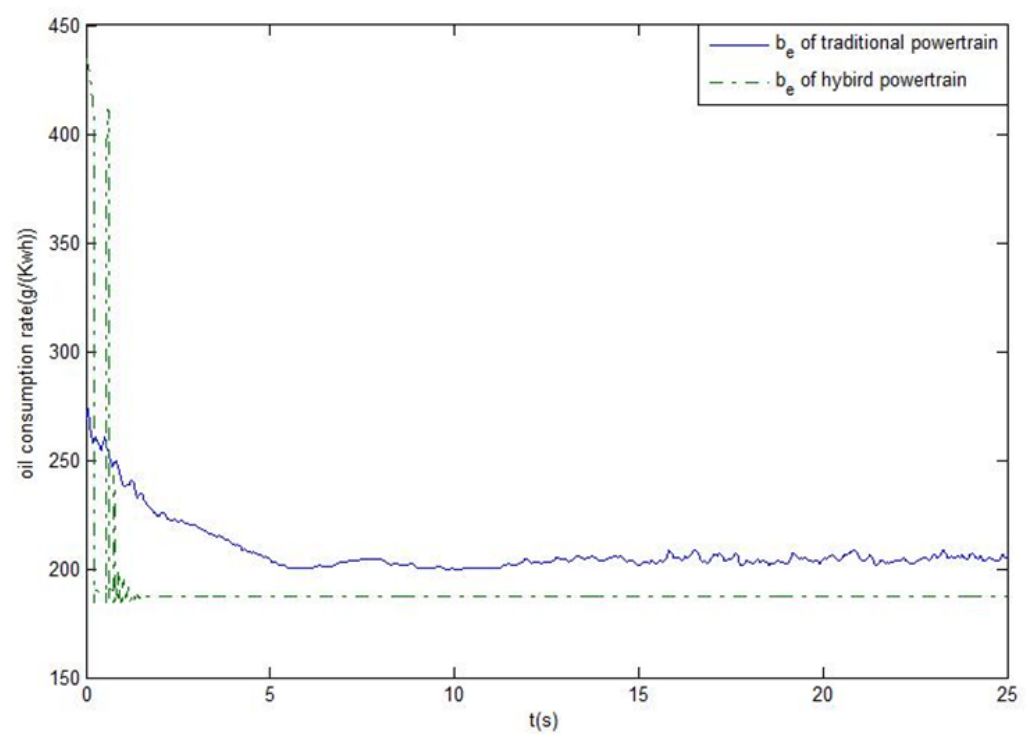

Fig.6 Fuel consumption comparison between traditional and hybrid power system

As shown in fig.6, compared with traditional internal-combustion driving track-type bulldozers, hybrid power system bulldozer can yield greater fuel efficiency by nearly $10 \%$.

\section{Conclusion}

In this paper, the motor's mathematical model for dual-motor-drive electric bulldozer is established. The simulation results show:

1) Simulation results demonstrate the validity of the hybrid power system model.

2) Simulation results show that matching of the parameters of the hybrid power system is reasonable.

3) Reasonable matching of the parameters of the hybrid power system is necessary to get a higher performance.

4) Compared with traditional internal-combustion driving track-type bulldozers, hybrid power system bulldozer can yield greater fuel efficiency by nearly $10 \%$. 


\section{References}

[1] Chen Ze yu, Zhang Cheng ning, Li Jun qiu, et al. Parameter Matching and Simulation for a Dual-motor -drive Electric Tracked Vehicle [J]. Vehicle \& Power Technology, 2009(4):12-14.

[2] E.M.Hackbarth. Tracked Vehicle Mechanics [M].Han Xue hai, Liu Kan, Zhou Yu-long, et al. Beijing: National Defence Industry Press, 1989:40-80.

[3] DONG Yu-gang, ZHANG Cheng-ning, SUN Feng-chun, WU Jing-bo. Engine-Generator's Control Strategy for Hybrid Electric Transmission Tracked Vehicle [J]. Transactions of Beijing Institute of Technology, 2010, 30(4):405-407.

[4] LI Jun-qiu, YAO Li-min, SUN Feng-chun, ZHANG Cheng-ning, GU Zhong-li. Dynamic Modeling and Simulation of Generator and Traction Battery Packs in an Electric Drive Vehicle [J]. Transaction of Beijing Institute of Technology, 2006, 26 (6):496-497.

[5] XIONG Hua-sheng, CAO Gui-jun, LU Lan-guang, QUYANG Ming-gao, LI Jian-qiu. Simulation system of Series Hybrid Powertrain for City Bus and Its Applications[J]. Journal of System Simulation, 2010, 22(5):1134-1135.

[6] Xiong Rui, He Hongwen, Wang Yi, Zhang Xiaowei. Study on ultracapacitor-battery hybrid power system for PHEV applications [J]. HIGH TECHNOLOGY LETTERS, 2010, 16 (1): 23-28.

[7] Hong-Wen He, Rui Xiong and Yu-Hua Chang. Dynamic Modeling and Simulation on a Hybrid Power System for Electric Vehicle Applications[J]. Energies, 2010,3: 1821-1830. 